\title{
Biomarkers of therapeutic response in primary nephrotic syndrome
}

\author{
Howard Trachtman
}

Received: 26 April 2012 / Accepted: 28 May 2012 /Published online: 19 June 2012

(C) IPNA 2012

To the Editors,

The recent retrospective study from Bennett et al. [1] in which they report that measurement of urinary concentration of NGAL (neutrophil gelatinase-associated lipocalin) enables discrimination of children with steroid-responsive from steroid-resistant nephrotic syndrome is potentially of great value in nephrology practice. In general, elevated urinary excretion of NGAL indicated the presence of steroidresistant disease caused by biopsy-confirmed focal segmental glomerulosclerosis (FSGS) in most of the cases. The authors claim that their findings represent the first description of a simple urine test that could differentiate between these two clinical categories of glomerular disease. However, over 15 years ago, we described significantly higher urinary nitrite excretion in children with presumed minimal change nephrotic syndrome (MCNS) $(n=48)$ compared to children with FSGS $(n=10)$ [2]. The higher levels of nitrite in the urine were documented in children with MCNS regardless of whether they were in remission or relapse $(n=10)$ and were unaffected by concomitant therapy with corticosteroids or diuretics. These observations suggest that there are probably several urinary biomarkers that may enable distinction between steroid-responsive and steroidresistant disease in children with new-onset nephrotic syndrome. No single biomarker is likely to be totally effective in all patient groups.
However, following the lead of Devarajan and others [3] who have pioneered the use of urinary biomarkers in the diagnosis of acute kidney injury, I would suggest that investigators work together to develop a panel of suitable biomarkers that can be combined in an array and tested simultaneously in a single assay to enhance the sensitivity and specificity of these analytes in patients with new-onset primary nephrotic syndrome. Such an approach would be a welcome addition to the management of children and adolescents with this important clinical problem.

\section{References}

1. Bennett MR, Piyaphanee N, Czech K, Mitsnefes M, Devarajan P (2012) NGAL distinguishes steroid sensitivity in idiopathic nephrotic syndrome. Pediatr Nephrol 27:807-812

2. Trachtman H, Gauthier BG, Frank R, Futterweit S, Goldstein A, Tomczak J (1996) Increased urinary nitrite excretion in children with minimal change nephrotic syndrome. J Pediatr 128:173-176

3. Palevsky PM, Molitoris BA, Okusa MD, Levin A, Waikar SS, Wald R, Chertow GM, Murray PT, Parikh CR, Shaw AD, Go AS, Faubel SG, Kellum JA, Chinchilli VM, Liu KD, Cheung AK, Weisbord SD, Chawla LS, Kaufman JS, Devarajan P, Toto RM, Hsu CY, Greene T, Mehta RL, Stokes JB, Thompson AM, Thompson BT, Westenfelder CS, Tumlin JA, Warnock DG, Shah SV, Xie Y, Duggan EG, Kimmel PL, Star RA (2012) Design of Clinical Trials in Acute Kidney Injury: Report from an NIDDK Workshop on Trial Methodology. Clin J Am Soc Nephrol 7:844-850

H. Trachtman $(\bowtie)$

NYU Langone Medical Center - Pediatrics,

CTSI, 7th Floor, Room \#712 227 East 30th St.,

New York, NY 10016-9196, USA

e-mail: howard.trachtman@nyumc.org 